\title{
Optimization of wind power producer participation in electricity markets with energy storage in a way of Energy 4.0
}

\author{
I.L.R. Gomes ${ }^{1,2,3}$, H.M.I. Pousinho ${ }^{2}$, R. Melício ${ }^{1,2}$, V.M.F. Mendes ${ }^{1,4,5}$ \\ ${ }^{1}$ Departamento de Física, Escola de Ciências e Tecnologia, Universidade de Évora, Portugal \\ ruimelicio@gmail.com \\ ${ }^{2}$ IDMEC, Instituto Superior Técnico, Universidade de Lisboa, Lisbon, Portugal \\ ${ }^{3}$ ICT, Instituto de Ciências da Terra, Universidade de Évora, Portugal \\ ${ }^{4}$ Instituto Superior of Engenharia de Lisboa, Lisbon, Portugal \\ ${ }^{5}$ C-MAST Center for Mechanical and Aerospace Sciences and Technology
}

\begin{abstract}
This paper proposes a problem formulation to aid as a support information management system of a wind power producer having energy storage devices and participating in electricity markets. Energy storage can play an important role in the reduction of uncertainties faced by a wind power producer. Excess of conversion of wind energy into electric energy can be stored and then released at favorable hours. Energy storage provides capability for arbitrage and increases the revenue of the wind power producers participating in electricity markets. The formulation models the wind power and the market prices as stochastic processes represented by a set of convenient scenarios. The problem is solved by a powerful stochastic mixed integer linear programming problem. A case study using data from the Iberian Electricity Market is presented to show the aid of the formulation.
\end{abstract}

Keywords: Electricity markets; energy storage; mixed integer linear programming; stochastic optimization; wind power.

\section{Introduction}

The conference on climate change, conference of the Parties, COP21, held in Paris in December 2015 adopted a new treaty by 195 nations aiming to limit climate change to below $2{ }^{\circ} \mathrm{C}$, which would render the most of the fossil fuel reserves in the ground [1], if dangerous of global warming above this limit is to be avoided. Alternative energy conversion technology, mainly wind power (WP) and photovoltaic (PV) power are experiencing impressive falls in costs - with PV prices dropping more than $60 \%$ between 2009 and the end of 2016 [2]. Total renewable energy capacity installed in 2015 was enough to supply around $23 \%$ of total electricity generation, sustained by progress in solar $\mathrm{PV}$ and onshore wind that pushed up the growth of renewable energy capacity to a record high, exceeding $150 \mathrm{GW}$ in 2015, according to the International Energy Agency's Tracking Clean Energy progress analysis [3]. One of characteristic of exploitation of WP is the uncertainty on the availability of the source of energy. WP per se is not capable of ensuring continuing on power conversion during all day due to the uncertainty in the availability of energy source at different periods of day or at different periods of the year. The challenges associated with meeting the variation in demand while providing reliable services has motivated historical development of energy storage and large penetrations of variable generation increases the need for flexibility options [4]. Large scale RES 
integration without energy storage is said to be a challenge for future power systems [5]. Hence, storage technology plays an important role in the actual deregulated markets, providing capability for arbitrage, increasing the economic value of renewable energy sources (RES) [6].

\section{Relationship to Energy 4.0}

A new term regarding the sector of energy of the future is emerging - Energy 4.0 [7]. Energy 4.0 derives from a more sightsaw term, the industry 4.0 [8]. The availability of the data to aid the energy sector is ongoing and will play an important role in the efficiency, reliability, security and cyber-security of smart grids [9] in the context of Energy 4.0. For example, the efficiency, reliability and security of a wind power system having a storage device as way to harness RES is to be improved with the availability of the data, allowing the store and discharge of energy at adequate conditions. The change of pattern from the traditional electric grid to a smart one [10] paved the way for the future in the way of power systems enhancement. Intelligence in the form of new computing models, algorithms, and advanced analytics are prone to enable enhancement in decision making [11]. A smart system can be stated as an embedded system that incorporates advanced systems and provides sophisticated monitoring and control over how something happens in the system [12]. Power systems are extensively handlers of intelligence in the scope of Energy 4.0. But, challenges and menaces to the former energy conversion into electric energy are appearing at an unprecedented speed: increasing of intermittent RES; new transmission and distributions grids; the need of energy storage. The business regarding electric energy has changed at the same scale: new market players; new products; new decision-making methodology in energy trading; an increase on collection and flow of data. Particularly, in monitoring and high quality real-time data for the exploitation of WP are a valuable contribution to mitigate the implications of uncertainty, implying losses on profit of WP producers in electricity markets.

\section{State of the Art}

The uncertainty nature of WP makes the bidding of the producers a task needing the aid of support management systems to conveniently participate in electricity markets. So, as to properly accommodate the uncertainty in WP into the decision of bidding. Research efforts have been made on the methodology to take into consideration the loss of revenue of WP producers participating in electricity markets. A survey on data mining techniques applied to energy time series forecasting is presented in [13]. The research in WP can be classified in three main lines. The first one explores the WP producer ability of achieving bidding strategy with the goal of minimizing the expected costs of imbalances, using stochastic optimization [14]. This is achieved by formulating a single period optimization problem which envisages several possible scenarios of WP production and imbalance penalty costs. The second one explores the WP producer ability to convert the electrical energy in other type of energy that can be stored and 
used when justified [15-17]. The third one explores the use of financial options as a tool for WP producers to hedge against wind generation uncertainty [18].

Mixed integer linear programming (MILP) has been used with success for trading energy in electricity markets [19-20]. This paper follows the first line of research, introducing significant advances, where stochastic MILP is used in addition to a complete model of a vanadium redox flow battery [21] that provides the capability of arbitrage to the WP producer.

\section{Day-ahead Market and Balancing Market}

The problem formulation proposed is partially set for Iberian Electricity market (MIBEL) rules, i.e., intraday markets are not considered, since this is not in the scope of this paper. MIBEL is a pool-based market where all market players must submit their bids for a whole day at 10 a.m. of the previous day. The accepted bids program defines the unit commitment for the 24 hours of the next day. The marginal price and the volumes are established for the whole market by a matching between the purchasing and selling of energy. This market is called the day-ahead market. Also, the market players can present new bids during the day of energy delivery till at least 3 hours before the operation time to the market called intraday market.

A wind producer is subjected to the uncertainty on wind power, so one expects that the bid presented in day-ahead market is not necessarily in accordance with the production in due time, i.e., imbalances are expected. The system operator use a procedure for keep the balance between demand of energy and energy generation to cope with the imbalances. This market is called the balancing Market. This market in MIBEL subjects the producer to a price for the positive energy imbalance and another price for negative energy imbalance [22]. The imbalance incurred by a power producer with a power plant $k$ in time $t$ is stated as follows:

$$
d_{t}^{k}=P_{t s}^{k}-P_{t}^{k} .
$$

In (1) $P_{t s}^{k}$ is the physical delivering of energy in time $t$ and $P_{t}^{k}$ is the energy submitted bid in the day-ahead market.

An imbalance of a physical energy delivering is associated with a price ratio: positive and negative imbalances are associated with price ratios $\mathrm{pr}_{t}^{+}$and $p r_{t}^{-}$, respectively. The positive price ratio is stated as follows:

$$
p r_{t}^{+}=\frac{\lambda_{t}^{+}}{\lambda_{t}}, p r_{t}^{+} \leq 1 .
$$

The negative price ratio is defined as follows:

$$
p r_{t}^{-}=\frac{\lambda_{t}^{-}}{\lambda_{t}}, p r_{t}^{-} \geq 1 .
$$

In (2) and (3) $\lambda_{t}$ is the day-ahead market price, $\lambda_{t}^{+}$and $\lambda_{t}^{-}$are respectively the positive and negative imbalance prices. Consequently, the power plant $k$ at period $t$ has a profit given as follows:

$$
P R_{t}^{k}=\lambda_{t} P_{t}^{k}+\left(\lambda_{t} p r_{t}^{+} d_{t}^{k+}-\lambda_{t} p r_{t}^{-} d_{t}^{k-}\right)
$$


In (4) the first term represents the profit associated with the day-ahead market price $\lambda_{t}$ from an accepted production $P_{t}^{k}$. The term in brackets is associated with the income derived from the procedure of economic penalty. The positive and negative deviations are respectively quantified by $d_{t}^{k+}$ and $d_{t}^{k-}$ subjected to the constraint of at least one of the deviations is always null at a period $t$.

Although, the problem formulation proposed in this paper is set for MIBEL the formulation can easily be customized to other rules for day-ahead and balancing markets.

\section{Problem Formulation}

The goal of the optimization problem is the profit maximization. Profit maximization implies a convenient consideration of the economic impact of imbalance. The convenient consideration must ponder the uncertainty on market prices and on availability of energy in due time to be converted into electric energy to satisfy delivering. If there is a mismatch between the energy bid accepted at the close of the day-ahead market and the actual production, then eventual losses on profit can occur. The problem formulation models uncertainty on WP availability by a convenient selection of scenarios giving the set $S$ said to be the set of appropriate scenarios for the next day. A scenario $s$ has a probability $\pi_{s}$ of occurrence. The problem formulation is a sort of a two-stage stochastic optimization problem where the hourly bids and imbalances are first and second-stage variables, respectively. Generally, the two-stage stochastic MILP formulated in terms of a continuous random vector which accounts for all the uncertain parameters of the problem is numerically intractable. But, to cope with intractability the original random vector can be approximate by one with a finite number of realizations or scenarios, the scenario tree. Two-stage stochastic programming is characterized by considering decisions made in two stages: first-stage, having decisions made before the realization of the random variables; second-stage, having decisions made after knowing the realization of random variables and depending on the decisions made in first-stage. The stochastic MILP formulation embraces the day-ahead market and the balancing market and is stated as follows:

$$
\max \sum_{s=1}^{S} \sum_{t=1}^{T} \pi_{s}\left(\lambda_{t s} P_{t}+\lambda_{t s} p r_{t s}^{+} d_{t s}^{+}-\lambda_{t s} p r_{t s}^{-} d_{t s}^{-}\right) .
$$

General constraints

a) Energy offer constraint

$$
0 \leq P_{t} \leq P^{W \max }+P_{t}^{\text {Debat max }} .
$$

b) Output power of WP and energy storage device

$$
P_{t s}=P_{t s}^{W}-P_{t}^{\text {Chbat }}+P_{t}^{\text {Debat }} .
$$

Imbalance constraints

$$
\begin{gathered}
d_{t s}=P_{t s}-P_{t}, \forall t, \forall s \\
d_{t s}=d_{t s}^{+}-d_{t s}^{-}, \forall t, \forall s \\
0 \leq d_{t s}^{+} \leq P_{t s} u_{t s}, \forall t, \forall s \\
0 \leq d_{t s}^{-} \leq\left(P^{W \max }+P^{\text {Debat } \max }\right)\left(1-u_{t s}\right), \forall t, \forall s .
\end{gathered}
$$

In (6) the limit on the bid is set to be the rated power of the wind system plus the maximum power discharge of storage device. In (8) to (11) the imbalance is 
decomposed into the difference between the $d_{t s}^{k+}$ and the $d_{t s}^{k-}$ imbalances. In (5), if the imbalance is negative, the term $\lambda_{t s} p r_{t s}^{+} d_{t s}^{k+}$ is null and the term $\lambda_{t s} p r_{t s}^{-} d_{t s}^{k-}$ is subtracted, if the imbalance is positive the term $\lambda_{t s} p r_{t s}^{-} d_{t s}^{k-}$ is null and the term $\lambda_{t s} p r_{t s}^{+} d_{t s}^{k+}$ is added.

Constraints of energy storage device

a) Energy storage equation

$$
E_{t}^{\text {bat }}=E_{t-1}^{\text {bat }}+\eta^{\text {Chbat }} P_{t}^{\text {Chbat }}-\frac{1}{\eta^{\text {Debat }}} P_{t}^{\text {Debat }} .
$$

b) Energy storage limits

$$
0 \leq E_{t}^{\text {bat }} \leq E^{\text {bat max }} .
$$

c) Storage power limits

$$
\begin{gathered}
0 \leq P_{t}^{\text {Chbat }} \leq P_{t}^{\text {Chbat } \max } k_{t} . \\
0 \leq P_{t}^{\text {Debat }} \leq P_{t}^{\text {Debat max }}\left(1-k_{t}\right) .
\end{gathered}
$$

In (12) the balance of the energy in the storage device is imposed: $E_{t}^{b a t}$ and $E_{t-1}^{b a t}$ are the energy stored at hour $t$ and hour $t-1$, respectively; $\eta^{\text {Chbat }}$ and $\eta^{\text {Debat }}$ are the efficiency of charging and discharging, respectively; $P_{t}^{\text {Chbat }}$ and $P_{t}^{\text {Debat }}$ are the power of charge and discharge at hour $t$, respectively. The balance of the energy in the storage device in (12) is normally the one describing a Vanadium redox flow battery, assuming a null depth of discharge. This type of energy storage is one of the most promising technology for energy management to mitigate the variation and intermittence of WP.

In (13) the limit on the energy storage is set to be the rated power of energy storage device.

In (14) and (15) the control of energy storage device is described. If the energy storage device is charging the binary variable $k_{t}$ is 1 and (14) defines a nonempty box constant for the charging power. If the storage device is discharging (15) defines a nonempty box constant for the discharging power. The procedure for the optimization of WP producer participation in a day-ahead market with energy storage is shown in Fig. 1.

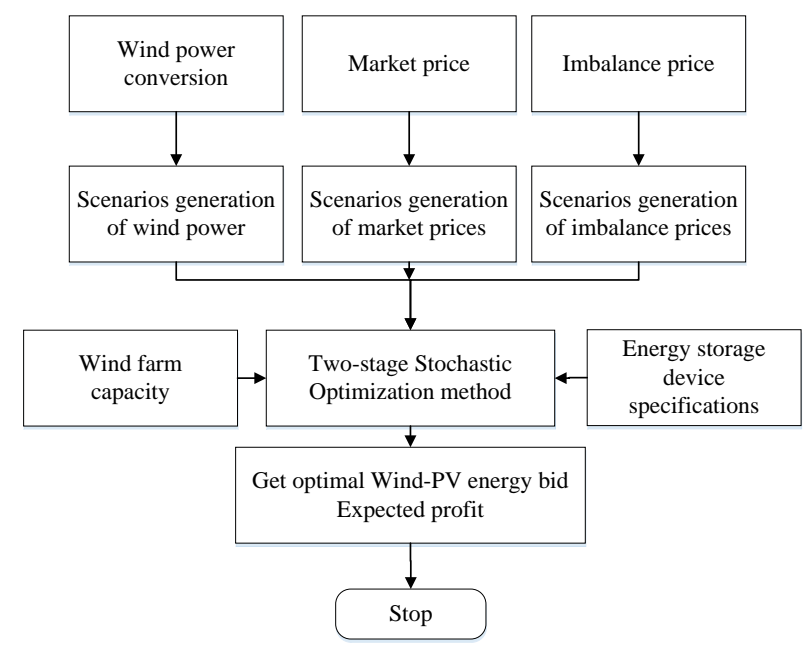

Fig. 1. Procedure for WP producer bidding strategy. 
In Fig. 1 the upper blocks are for scenario generation procedures obtained via historical data of wind speed, and historical data of MIBEL. After the blocks for scenario generation procedures, technical data blocks access the wind and energy storage device speciation to deliver the information into the block implementing the MILP approach for the two-stage stochastic problem formulation solved by GAMS/CPLEX.

\section{Case Study}

MIBEL data is used for addressing the day-ahead and the balancing markets to be used in the case study. The case study is based on a wind farm sited in Portugal with rated power of $100 \mathrm{MW}$ and an energy storage device with rated power of $30 \mathrm{MW}$. The dayahead market prices and the imbalance prices are reported in [23]. The bidding is for a $24 \mathrm{~h}$ horizon on an hourly basis. 10 hourly scenarios are obtained for wind power, for day-ahead market prices and for imbalance prices. The numerical simulation has been performed on a $1.6 \mathrm{GHz}$ based processor with $4 \mathrm{~GB}$ of RAM. The CPU time is of 5.7 seconds.

The hourly day-ahead market prices scenarios and the imbalance prices scenarios are shown in Fig. 2.
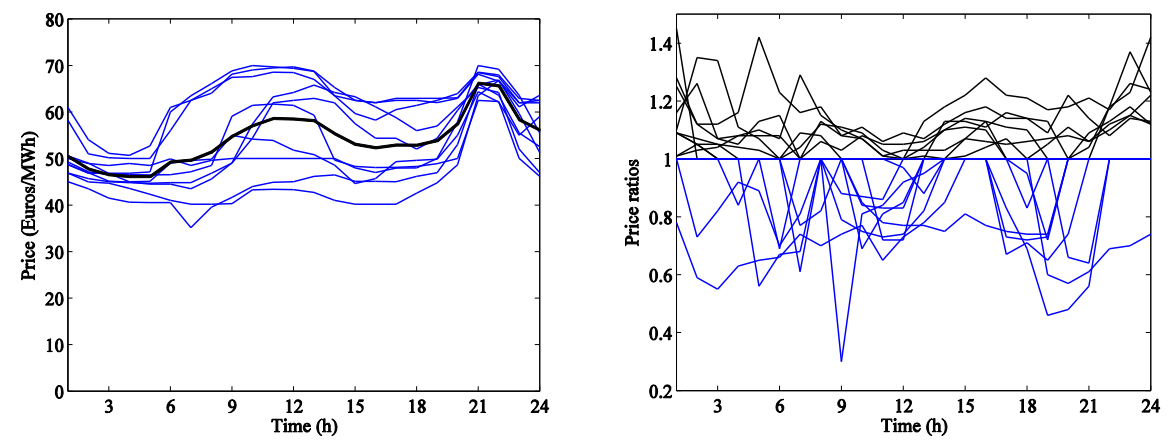

Fig. 2. Left: Electricity price (average - black line); Rigth: price ratios: positive (blue lines), negative (black lines).

The hourly WP scenarios are shown in Fig. 4.

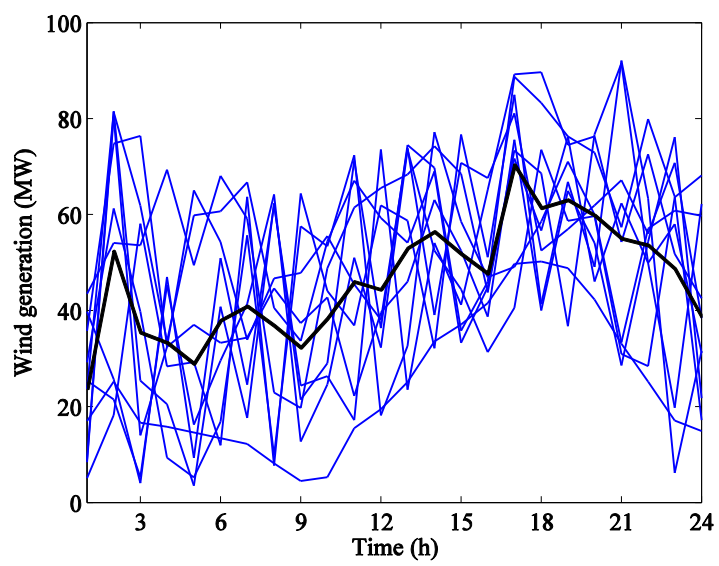

Fig. 4. WP scenarios and average scenario (black line). 
The energy traded and the day-ahead market price is shown in Fig. 5.

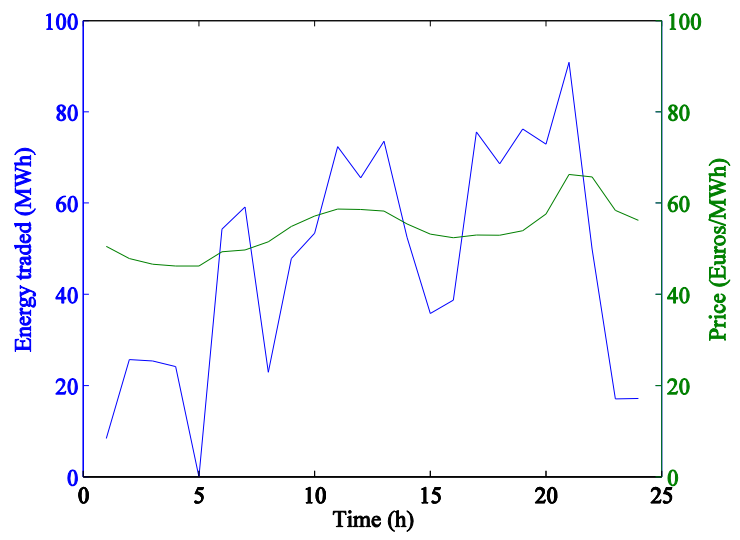

Fig. 5. Energy traded and day-ahead market price.

Fig. 5 shows that the higher levels of bid occur in hours of likely high market prices: around $11 \mathrm{~h}$ and $14 \mathrm{~h}$ and around $17 \mathrm{~h}$ and $21 \mathrm{~h}$.

The energy stored and the day-ahead market price are shown in Fig. 6.

Fig. 6 shows that although of the $24 \%$ loss of energy of charging and discharging cycle, storing is called for optimal bidding. The energy storage device is as expected charging in $4 \mathrm{~h}$ and $5 \mathrm{~h}$, having likely low market prices and favourable for positive imbalance, having more intensive charge at the lowest likely price $5 \mathrm{~h}$.

The discharged energy and the day-ahead market price are shown in Fig. 7.

Fig. 6 and Fig. 7 show that the energy storage favours a convenient accommodation of energy, storing and delaying conveniently the use of energy to a more profitable hour: charging in $4 \mathrm{~h}$ and $5 \mathrm{~h}$ and releasing at $21 \mathrm{~h}$. The total profit is $5974.65 €$.

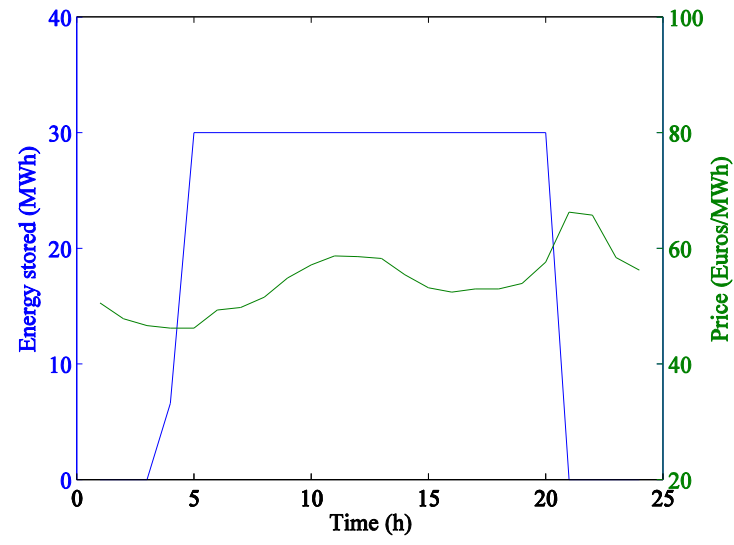

Fig. 6. Energy stored and day-ahead market price. 


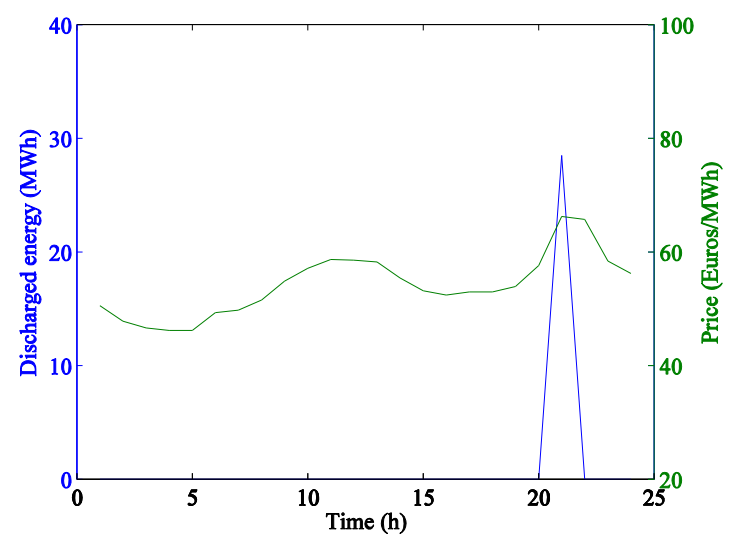

Fig. 7. Discharged energy and day-ahead market price.

\section{Conclusion}

A problem formulation is proposed to aid as a support information management system for bidding of WP having an energy storage device in day-ahead and balancing electricity markets. Energy storage is shown to provide the capability of arbitrage, storing energy and discharging at conveniently hours. Wind generation and market prices are modeled as a set of scenarios to be treated by a stochastic methodology suitable for problems with uncertainty. In addition, the MILP allows modelling of the energy storage device, using a binary variable associated with charging/discharging. The method is applied to a case study, where real measured data for WP and for market prices are used.

\section{Acknowledgments}

To thank the Millennium BCP Foundation for the financial support; the current study was funded in part by Fundação para a Ciência e a Tecnologia (FCT), under project UID/EMS/00151/2013 C-MAST, with reference POCI-01-0145-FEDER-007718.

\section{References}

1. Graaf, T.V.: Is OPEC dead? Oil exporters, the Paris agreement and the transition to postcarbon world. Energy Research and Social Science 23, 182-188 (2017).

2. Vandyck, T.: Keramidas, K., Kitous, B., Vrontisi, Z., A global stocktake of the Paris pledges: Implications for energy systems and economy. Global Environ. Change 41, 46-63 (2016)

3. Rajgor, G.; Greater acceleration of renewables required to meet COP21 goal. Renewable Energy 17 (5), 175-177 (2016)

4. Denholm, P., Ela, E., Kirby, B., Milligan, M.: The role of energy storage with renewable electricity generation. National Renewable Energy Laboratory, Colorado, USA (2010)

5. Beaudin, M., Zareipour, H., Schellenberglabe, A., Rosehart, W.: Energy storage for mitigating the variability of renewable electricity sources: an updated review. Energy for Sustainable Development 14(4), 302-314 (2010)

6. Divya, K.C., Østergaard, J.: Battery energy storage technology for power systems-an overview. Electric Power Systems Research 79(4), 511-520 (2009)

7. Lang, M.: From industry 4.0 to energy 4.0. future business, models and legal relations. Digitalisierung in der Energiewirtschaft XX, Jahrestagung Institut für Berg- und Energierecht, (2016) 
8. Batista, N.C., Melicio, R., Mendes, V.M.F.: Services enabler architecture for smart grid and smart living services providers under industry 4.0. Energy and Buildings 141, 16-27 (2017)

9. Batista, N.C., Melício, R., Mendes, V.M.F.: Layered smart grid architecture approach and field tests by ZigBee technology. Energy Conversion and Management 88, 49-59 (2014)

10. Arsan, T.: Smart systems: from design to implementation of embedded smart systems. In: 13th International Symposium on Smart MicroGrids for Sustainable Energy Sources enabled by Photonics and IoT Sensors, Nicosia, Cyprus, 59-64 (2016)

11. Gomes, I.L.R, Pousinho, H.M.I, Melício, R., Mendes, V.M.F.: Bidding and optimization strategies for wind-pv systems in electricity markets assisted by CPS. Energy Procedia 106, 111-121 (2016)

12. Glesner, M., Philip, F.: Embedded systems design for smart system integration. In: IEEE Computer Society Annual Symposium on VLSI, Natal, Brazil 32-33 (2013)

13. Martínez-Álvarez, F., Troncoso, A., Asensio-Cortés, G., Riquelme, J.C.: A survey on data mining techniques applied to electricity-related time series forecasting. Energies, 8 (11), 13162-13193 (2015)

14. Matevosyan, J., Söder, L.: Minimization of imbalance cost trading wind power on the shortterm power market. IEEE Transactions on Power Systems 21(3), 1396-1404 (2006)

15. González-Garcia, J., Muela, R.M.R., Santos, L.M., González, A.M.: Stochastic joint optimization of wind generation and pumped-storage units in an electricity market. IEEE Transaction on Power Systems 23(2), 460-468 (2008)

16. Angarita, J.L., Usaola, J., Martínez-Crespo, J.: Combined hydro-wind generation bids in a pool-based electricity market. Electric Power Systems Research 79(7), 1038-1046 (2009)

17. Sundararagavan, S., Baker, E.: Evaluating energy storage technologies for wind power integration. Solar Energy 86(9), 2707-2717 (2012)

18. Hedman, K.W., Sheble, G.B.: Comparing hedging methods for wind power: using pumped storage hydro units vs. options purchasing. In: Proc. International Conference on Probabilistic Methods Applied to Power Systems - PMAPS, Stockholm, Sweden 1-6 (2006)

19. Laia, R., Pousinho, H.M.I., Melicio, R., Mendes, V.M.F.: Self-scheduling and bidding strategies of termal units with stochastic emission constraints. Energy Conversion and Management 89, 975-984 (2015)

20. Laia, R., Pousinho, H.M.I., Melicio, R., Mendes, V.M.F.: Bidding strategy of wind-thermal energy producers. Renewable Energy 99, 673-681 (2016)

21. Arribas, B.N., Melício, R., Teixeira, J.G., Mendes, V.M.F.: Vanadium redox flow battery storage system linked to the electric grid. In: Proc. ICREPQ - Renewable Energy and Power Quality Journal 1(14), 1025-1030 (2016)

22. Gomes, I.L.R, Pousinho, H.M.I, Melício, R., Mendes, V.M.F.: Stochastic coordination of joint wind and photovoltaic systems with energy storage in day-ahead market. Energy 124, 310-320 (2017)

23. http://www.esios.ree.es/web-publica/ accessed February 8 (2017) 